\title{
Homocysteine lowering treatment improved outcomes after percutaneous coronary intervention
}

\author{
Schnyder G, Roffi M, Flammer Y, et al. Effect of homocysteine-lowering therapy with folic acid, vitamin B12, and vitamin \\ B6 on clinical outcome after percutaneous coronary intervention: the Swiss Heart study: a randomized controlled trial. \\ JAMA 2002;288:973-9. \\ QUESTION: In patients having percutaneous coronary intervention (PCI), does \\ homocysteine lowering treatment with folic acid, vitamin $B_{12}$, and vitamin $B_{6}$ reduce \\ adverse coronary outcomes?
}

\section{Design}

Randomised (unclear allocation concealment*), blinded (clinicians, patients, and outcome assessors), ${ }^{*}$ placebo controlled trial with 12 months of follow up.

\section{Setting}

A university hospital in Bern, Switzerland.

\section{Patients}

553 patients (mean age 63 y, 80\% men) who received angioplasty to treat at least 1 significant coronary stenosis $(\geq 50 \%)$. Exclusion criteria were unstable angina, myocardial infarction (MI) within the past 2 weeks, renal insufficiency, or receipt of vitamin supplements. Follow up was $83 \%$; all patients were included in the analysis.

\section{Intervention}

Patients were allocated to homocysteine lowering treatment with folic acid, $1 \mathrm{mg} /$ day; vitamin $\mathrm{B}_{12}, 400 \mu \mathrm{g} /$ day; and vitamin $\mathrm{B}_{6}, 10 \mathrm{mg} /$ day $(\mathrm{n}=272)$ or to placebo $(\mathrm{n}=281)$ for 6 months.

\section{Main outcome measures}

Adverse events defined as all cause mortality, cardiac death, nonfatal MI, need for repeated revascularisation for proven ischaemia, or a composite of adverse events.

\section{Main results}

Analysis was by intention to treat. The composite endpoint of any major coronary adverse outcome was lower in the homocysteine lowering group than the placebo group, as was the need for repeated revascularisation and repeated target lesion revascularisation (table). Adjustment for age, sex, and risk factors known to influence the need for repeated revascularisation did not affect the results. The groups did not differ for nonfatal MI, cardiac death, or all cause mortality.

\section{Conclusion}

In patients having PCI, homocysteine lowering treatment with folic acid, vitamin $B_{12}$, and vitamin $B_{6}$ reduced the need for repeated revascularisation and adverse coronary outcomes.

*See glossary.

ent v placebo after percutaneous coronary interventiont

Homocysteine lowering treatment v placebo afte
Outcomes at $\quad$ Homocysteine

\begin{tabular}{|c|c|c|c|c|}
\hline $\begin{array}{l}\text { Outcomes at } \\
1 \text { year }\end{array}$ & $\begin{array}{l}\text { Homocysteine } \\
\text { lowering }\end{array}$ & Placebo & RRR $(95 \%$ Cl) & NNT (CI) \\
\hline Composite outcome & $15.4 \%$ & $22.8 \%$ & $69 \%$ (50 to 97$)$ & 15 (9 to 167$)$ \\
\hline $\begin{array}{l}\text { Repeated } \\
\text { revascularisation }\end{array}$ & $14.0 \%$ & $19.9 \%$ & $29 \%(1.8$ to 46$)$ & 18 (11 to 281$)$ \\
\hline $\begin{array}{l}\text { Repeated target lesion } \\
\text { revascularisation }\end{array}$ & $9.9 \%$ & $16.0 \%$ & $37 \%$ (4.6 to 57$)$ & 17 (11 to 136$)$ \\
\hline
\end{tabular}

tComposite outcome included death, cardiac death, nonfatal myocardial infarction, or need for repeated revascularisation. Abbreviations defined in glossary; RRR, NNT, and Cl calculated from data in article using Cox proportional hazards ratio.

\section{COMMENTARY}

Systematic reviews have consistently shown a strong relation between elevated blood concentrations of homocysteine and risk of atherothrombotic vascular disease. ${ }^{1-2}$ Furthermore, blood concentrations of homocysteine can be lowered in most patients using folate containing multivitamin treatment. ${ }^{3}$ However, uncertainty still exists about the relation between homocysteine and vascular disease, especially whether it is causal (and modifiable) or confounded (high homocysteine concentrations may simply be a marker of another causal vascular risk factor), or whether high homocysteine concentrations in the blood may simply be a consequence of the atherosclerotic disease process or it complications. ${ }^{4}$

The study by Schnyder et al provides further support for a causal association between homocysteine and vascular disease by showing, for the first time, a reduction in major clinical vascular events, including death, MI, and target vessel revascularisation with folate based homocysteine lowering treatment. Although the risk reductions for death or MI were not statistically significant, the consistency of the treatment effect compared with the overall risk reduction suggests that the reduction in these outcomes is real.

A potential limitation of this study is that $13 \%$ of patients were lost to follow up; imbalances in clinical outcomes between the 2 treatment groups after loss to follow up could alter the study results. However, this is unlikely because the baseline characteristics and disease severity of patients lost to follow up did not differ from the rest of the study population and a similar proportion was lost from both treatment groups.

What are the implications for clinical practice? Although causality of association between homocysteine and atherothrombosis remains unproven, the substantial benefits of simple, inexpensive, nontoxic, multivitamin treatment seem to provide a strong rationale for routine use of folic acid and vitamins $B_{6}$ and $B_{12}$ in patients receiving PCI. However, confirmatory data further evaluating the "homocysteine hypothesis" of atherothrombosis would be welcome.

John Eikelboom, MD Royal Perth Hospital Perth Western Australia Australia

1 Boushey CJ, Beresford SA, Omenn GS, et al. A quantitative assessment of plasma homocysteine as a risk factor for vascular disease. Probable benefits of increasing folic acid intakes. JAMA 1995;274:1049-57.

2 Homocysteine Studies Collaboration. Homocysteine and risk of ischemic heart disease and stroke: a meta-analysis. IAMA 2002;288:2015-22.

3 Homocysteine Lowering Trialists' Collaboration. Lowering blood homocysteine with folic acid based supplements: meta-analysis of randomised trials. BM 1998.316:894-8.

4 Eikelboom JW, Lonn E, Genest J Jr, et al. Homocyst(e)ine and cardiovascular disease: a critical review of the epidemiologic evidence. Ann Intern Med 1999;131:363-75. 